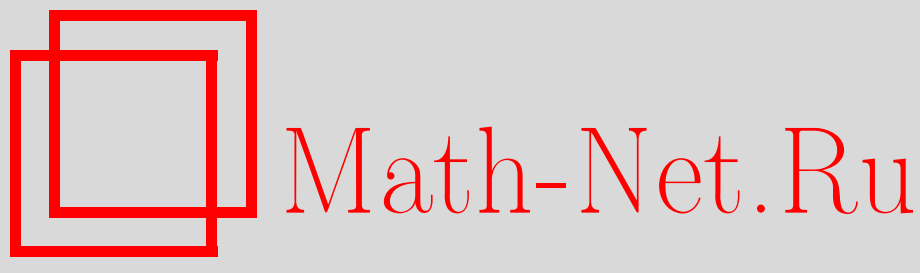

В. В. Прелов, Теория информации в научной деятельности Р. Л. Добрушина, УМН, 1997, том 52, выпуск 2, 9-13

DOI: https://doi.org/10.4213/rm1582

Использование Общероссийского математического портала Math-Net.Ru подразумевает, что вы прочитали и согласны с пользовательским соглашением

http://www. mathnet.ru/rus/agreement

Параметры загрузки:

IP: 18.234 .156 .22

26 апреля 2023 г., 16:42:50

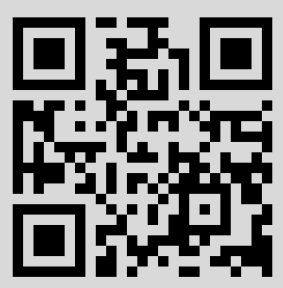




\section{ТЕОРИЯ ИНФОРМАЦИИ \\ В НАУЧНОЙ ДЕЯТЕЛЬНОСТИ Р. Л. ДОБРУШИНА}

\section{В. В. ПРЕЛОВ}

Интерес к теории информации возник у Р. Л. Добрушина в конце пятидесятых годов под влиянием А.Н. Колмогорова, активно пропагандировавшего в то время среди молодых математиков идеи теории, основы которой заложил К. Шеннон в 1948 году [1]. Активная работа Р. Л. Добрушина над различными проблемами теории информации продолжалась около шести лет, однако и в дальнейшем, когда основные его научные интересы сместились в область математической физики и связанных с ней задач теории случайных процессов и полей, он не потерял к ней интерес, был в курсе всех ее новейших достижений, публикуя время от времени совместно со своими учениками и коллегами статьи по различным вопросам теории информации.

Несмотря на сравнительно непродолжительньй период активных занятий теорией информации, Р. Л. Добрушин получил в этой области много замечательных результатов. Всего по теории информации им было опубликовано около тридцати научных работ. Достаточно подробный обзор этих работ содержится в [2], где приведена и полная библиография. Здесь же мы остановимся лишш на некоторых наиболее значительных с нашей точки зрения результатах Р. Л. Добрушина в теории информации.

Несомненно, самым выдаюшимся достижением Р. Л. Добрушина в теории информации стало нахождение им наиболее общих, простых и естественных условий справедливости основной теоремы теории информации (назьваемой теоремой Шеннона), устанавливающей необходимые и достаточные условия возможности надежной передачи информации по каналам связи. Основная работа на эту тему [3] была опубликована Р. Л. Добрушиным в 1959 году в "Успехах математических наук" и вошла в качестве главной составляющей в его докторскую диссертацию, блестяще защищенную им в 1962 году. Эта работа Р. Л. Добрушина получила вскоре всемирное признание и поставила ее автора в один ряд с мировыми лидерами математической теории информации. Здесь нет возможности сколько-нибудь подробно сформулировать основные результаты указанной работы. Отметим лишь, что условия справедливости теоремы Шеннона сформулированы Р. Л. Добрушиным в терминах введенных им понятий 
информационной устойчивости последовательности передающих устройств и последовательности сообщений, опирающихся на следующее определение информашионной устойчивости последовательности пар случайных величин. Согласно Р. Л. Добрушину последовательность пар случайных величин $\left(X_{n}, Y_{n}\right)$ назьвается информационно-устойчивой, если $I\left(X_{n} ; Y_{n}\right)<\infty$ при всех $n$ и $\left[i_{n}\left(X_{n}, Y_{n}\right) / I\left(X_{n} ; Y_{n}\right)\right] \rightarrow 1$ при $n \rightarrow \infty$ по вероятности (где $I\left(X_{n} ; Y_{n}\right)$ - (шенноновская) взаимная информация между случайными величинами $X_{n}$ и $Y_{n}$, а $i_{n}\left(X_{n}, Y_{n}\right)$ - информационная плотность $X_{n}$ и $Y_{n}$, определяемая как логарифм производной Радона-Никодима совместного распределения пары $\left(X_{n}, Y_{n}\right)$ по отношению к произведению маргинальных распределений $X_{n}$ и $\left.Y_{n}\right)$.

Важное значение имеют результаты Р. Л. Добрушина [4]-[7], посвященные распространению теорем Шеннона на каналы и источники сообшений с неизвестными или частично известными параметрами, когда требуется построить единые методы передачи информации или единые методы кодирования источника (квантования сообщений) для любого возможного канала или источника, принадлежашего заданному (и известному) классу каналов или источников сообшений. Р. Л. Добрушиным (одновременно с некоторыми американскими авторами) был предложен минимаксньй принцип определения пропускной способности каналов с неизвестньми параметрами и найдены некоторые достаточные условия справедливости теоремы Шеннона. Следует отметить, что в полном объеме теорема Шеннона для подобных каналов доказана лишь сравнительно недавно, хотя основной шаг был сделан в работе Р. Л. Добрушина и С. З. Стамблера [8]. Теорема Шеннона для источников с неизвестньми параметрами была доказана Р. Л. Добрушиным при аналогичном минимаксном подходе к определению $\varepsilon$-энтропии класса источников сообщений.

Р. Л. Добрушин дал строгое математическое описание каналов без памяти с ошибками в синхронизации [9], служаших моделью реальных каналов, в которых происходят сбои синхронизации из-за того, что некоторые передаваемые символы могут бесследно исчезать (вьпадение символов), а другие внезапно появляться (вставка символов). Он показал, что интервалы длины $n$ таких каналов образуют информационно устойчивую последовательность, что позволяет доказать для них теорему Шеннона. Однако для каналов с ошибками в синхронизации возникает новая проблема проблема сушествования хороших методов передачи бесконечной последовательности символов источника, поскольку в отличие от обычных каналов (в которых ошибки в синхронизации отсутствуют) последовательное использование хороших блоковых кодов не обеспечивает, вообе говоря, надежной передачи такой бесконечной последовательности. Теорема Шеннона в случае передачи бесконечной длительности для таких каналов также была доказана Р. Л. Добрушиным в [9].

Одной из центральных проблем теории информации является исследование оптимальной вероятности ошибки $e(R, n)$ и функции надежности

$$
E(R)=-\lim _{n \rightarrow \infty} \frac{\log e(R, n)}{n}
$$

как функций скорости $R$ и длины $n$ кода при передаче по различным каналам связи. И в этой области Р. Л. Добрушин получил ряд глубоких результатов [10]-[14]. Обобщая результат Элайеса для двоичного симметричного канала без памяти, он нашел 
значение $E(R)$ при $R>R_{\text {crit }}$ и указал верхние и нижние границы $E(R)$ при $R<R_{\text {crit }}$ ( $R_{\text {crit }}$ - некоторая константа, назьваемая критической скоростью) для произвольного дискретного канала без памяти, любая строка (столбец) матрицы переходной вероятности которого является перестановкой ее первой строки (столбца). Более того, для таких каналов при $R>R_{\text {crit }}$ он получил и более точное асимптотическое выражение

$$
\log e(R, n)=-n E(R)+\alpha_{R} \log n+O(1), \quad n \rightarrow \infty,
$$

где $\alpha_{R}$ - некоторая константа, и показал, что асимптотика логарифма вероятности ошибки почти любого кода со скоростью $R>R_{\text {crit }}$ (в случае, когда слова кода выбираются случайно и независимо друг от друга с соответствуюшим распределением) совпадает с асимптотикой $\log e(R, n)$ с точностью до членов порядка $O(1), n \rightarrow \infty$. Для двоичных симметричных каналов со стиранием Р. Л. Добрушин нашел главный член асимптотики при $n \rightarrow \infty$ логарифма оптимальной вероятности ошибки при любом фиксированном числе сообщений. Обобщая другой результат Элайеса для двоичных симметричных каналов без памяти, он показал, что для любого дискретного симметричного канала без памяти почти любой груповой код асимптотически опти-

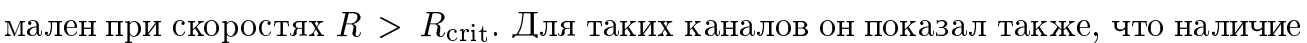
обратной связи не изменяет функцию надежности при $R>R_{\text {crit }}$.

Р.Л. Добрушин внес фундаментальный вклад в исследование основных теоретико-информационных характеристик и получил важные результаты практически во всех разделах теории информашии шестидесятых годов. Он открыл некоторые новые свойства информации, а ряд известных доказал в наибольшей общности [3], исследовал важный вопрос о возможности перехода к пределу под знаками информации и энтропии [15] и предложил эффективный метод статистического оценивания энтропии стационарной последовательности из наблюдений [16]. Несколько совместных работ Р. Л. Добрушина посвяшены исследованию $\varepsilon$-энтропии и пропускной способности некоторых специальных классов источников и каналов, представляюших как теоретический, так и практический интерес [17]-[21], а также изучению сложности некоторых близких к оптимальным методов кодирования на схемах из функциональных элементов [22], [23] и сложности самокорректирующихся схем из ненадежных элементов, реализуюших заданную функцию [24], [25]. Р. Л. Добрушин был автором первой советской работы по последовательному декодированию [26], где исследовались вопросы сложности некоторых методов последовательного декодирования.

Помимо чисто научной деятельности в области теории информации Р. Л. Добрушин много сил и энергии отдавал широкой пропаганде идей и методов теории информации, предостерегая однако от поверхностного использования ее весьма обших понятий и результатов во всех областях научных исследований, использующих понятия информации, энтропии и т. п. Он был одним из инициаторов издания на русском языке сборника трудов К. Шеннона по теории информации и кибернетике, а также редактором большинства переведенных на русский язык монографий по математической теории информации. Р. Л. Добрушин написал несколько прекрасных обзоров по теории информации и был соавтором многих статей по теории информации для Математической энциклопедии и Энщиклопедии кибернетики. К сожалению, его стремление к постоянному улучшению и переработке уже написанного не позволило издать две написанные им монографиии (одна из них в соавторстве) по теории информации. 
Уже в начале шестидесятых годов Р. Л. Добрушин впервые начал включать некоторые разделы теории информации в обязательные курсы лекций по теории вероятностей, которые он читал на механико-математическом факультете МГУ. Там же он начал вести научньй семинар и прочитал первьй спецкурс по теории информации. Несколько позже Р. Л. Добрушин (вместе с М. С. Пинскером) организовал обшемосковский семинар по теории информащии, которьй после его перехода на работу в Институт проблем передачи информации (ИППИ) стал проходить в здании этого института. В ИППИ Р. Л. Добрушин создал лабораторию, которую возглавлял на протяжении тридщати лет вплоть до своей кончины. В течение всех этих лет теория информации оставалась одним из главных направлений научных исследований сотрудников этой лаборатории.

С самого начала издания (1965 год) журнала "Проблемы передачи информации" Р.Л. Добрушин был заместителем главного редактора, вьполняя фактически роль главного научного редактора. Он организовал также раздел теории информации в реферативном журнале "Математика" и на протяжении многих лет был его редактором. Длительное время Р. Л. Добрушин занимал пост председателя секции теории информации в Научном совете "Кибернетика" при Президиуме АН СССР. Он был одним из главных организаторов регулярных международных симпозиумов по теории информации, проводившихся в нашей стране.

\section{СПИСОК ЛИТЕРАТУРЫ}

[1] Shannon C. E. A mathematical theory of communication // Bell System Tech. J. 1948. V. 27. P. 379-423, 623-656.

[2] Памяти Роланда Львовича Добрушина // Пробл. передачи информ. 1996. Т. 32. № 3. C. 3-24.

[3] Добрушин Р. Л. Общая формулировка основной теоремш Шеннона в теории информации // УМН. 1959. Т. 14. №6. С. 3-104.

[4] Добрушин Р.Л. Оптимальная передача информации по каналу с неизвестньми параметрами // Радиотехника и электроника. 1959. Т. 4. №12. С. 1951-1956.

[5] Добрушин Р. Л. Единые способы передачи информации для дискретных каналов без памяти и сообщений с независимьми компонентами // Докл. АН СССР. 1963. Т. 148. №6. C. $1245-1248$.

[6] Добрушин Р. Л. Единые способы передачи информации - общий случай // Докл. АН CСCР. 1963. Т. 149. № 1. С. 16-19.

[7] Добрушин Р. Л. Единые способы оптимального квантования сообщений // Пробл. кибернетики. 1970. № 22. С. 107-156.

[8] Добрушин Р. Л., Стамблер С.З. Теоремы кодирования для классов произвольно изменяющихся во времени дискретных каналов без памяти // Пробл. передачи информ. 1975. T. 11. № 2. C. 3-22.

[9] Добрушин Р. Л. Теорема Шеннона для каналов с ошибками в синхронизации // Пробл. передачи информ. 1967. Т. 3. № 4. С. 18-36.

[10] Добрушин Р.Л.Асимптотика вероятностей ошибки при передаче информации по каналу без памяти с симметрической матрицей вероятностей перехода // Докл. АН СССР. 1960. T. 133. № 2. C. 265-268.

[11] Добрушин Р. Л. Оптимальные бинарные коды для малшіх скоростей передачи информации // Теория вероятн. и ее примен. 1962. Т. 7. № 2. С. 203-213.

[12] Добрушин Р.Л.Асимптотические оценки вероятности ошибки при передаче сообщения по дискретному каналу без памяти с симметрической матрицей вероятностей перехода // Теория вероятн. и ее примен. 1962. Т. 7. № 3. С. 283-311. 
[13] Добрушин Р.Л.Асимптотическая оценка вероятности ошибки при передаче сообщения по каналу без памяти с использованием обратной связи // Пробл. кибернетики. 1962. № 3. C. $161-168$.

[14] Добрушин Р. Л. Асимптотическая оптималшность групповых и систематических кодов для некоторых каналов // Теория вероятн. и ее примен. 1963. Т. 8. № 1. С. 52-66.

[15] Добрушин Р. Л. Пределшньй переход под знаком информации и энтропии // Теория вероятн. и ее примен. 1960. Т. 5. №1. С. 29-37.

[16] Добрушин Р. Л. Упрощенньй метод экспериментальной оценки энтропии стационарной последовательности // Теория вероятн. и ее примен. 1958. Т. 3. № 4. С. 462-464.

[17] Добрушин Р. Л., Хургин Я.И., Цыбаков Б.С.Приближенное вычисление пропускной способности радиоканалов со случайными параметрами // Труды Всес. совещ. по теории вероятн. и матем. статист. (Ереван. 19-25 сент. 1958). Ереван: Изд-во АН АрмССР. C. $164-171$.

[18] Dobrushin R.L., Tsybakov B.S. Information transmission with additional noise // IEEE Trans. Inform. Theory. 1962. V. 8. № 5. P. 293-304.

[19] Добрушин Р. Л., Пинскер М. С., Ширяев А.Н. Применение понятия энтропии в проблемах обнаружения сигнала на фоне шума // Литов. матем. сб. 1963. Т. 3. №1. C. $107-122$.

[20] Добрушин Р. Л., Пинскер М.С. Память увеличивает пропускную способность // Пробл. передачи информ. 1969. Т. 5. № 1. С. 94-95.

[21] Бассалыго Л. А., Добрушин Р. Л. Эпсилон-энтропия гиббсовского поля // Пробл. передачи информ. 1987. Т. 23. № 1. С. 3-15.

[22] Dobrushin R. L., Gelfand S.I. Complexity of asymptotically optimal code realization by constant depth schemes // Problems Control Inform. Theory. 1972. V. 1. № 3-4. P. 197-215.

[23] Dobrushin R. L., Gelfand S.I., Pinsker M.S. On complexity of coding // Proc. Second Internat. Symp. on Inform. Theory. Zahkadzor, Armenia, Academiai Kiado, Budapest. P. 177-184.

[24] Добрушин Р. Л., Ортюков С.И. О нижней оценке для избыточности самокорректирующихся схем из ненадежных функциональных элементов // Пробл. передачи информ. 1977. T. 13. № 1. C. 82-89.

[25] Добрушин Р. Л., Ортюков С. И. Верхняя оценка для избыточности самокорректирующихся схем из ненадежных функциональных элементов // Пробл. передачи информ. 1977. T. 13. № 3. C. 56-76.

[26] Добрушин Р.Л. По поводу последовательного декодирования методом Возенкрафота-Рейффена // Пробл. кибернетики. 1964. № 12. С. 113-123. 